\title{
Effects of different emulsifier substitutes on artisanal ice cream quality --Manuscript Draft--
}

\begin{tabular}{|c|c|}
\hline Manuscript Number: & LWT-D-20-04443R2 \\
\hline Keywords: & alpha-cyclodextrin; citrus fibers; phospholipids; legume proteins; rice proteins. \\
\hline Corresponding Author: & $\begin{array}{l}\text { Cristina Alamprese, Prof., PhD } \\
\text { University of Milan Department of Food Environmental and Nutritional Sciences: } \\
\text { Universita degli Studi di Milano Dipartimento di Scienze per gli Alimenti la Nutrizione e } \\
\text { l'Ambiente } \\
\text { Milan, ITALY }\end{array}$ \\
\hline First Author: & Eleonora Loffredi, Dr \\
\hline \multirow[t]{2}{*}{ Order of Authors: } & Eleonora Loffredi, Dr \\
\hline & Maria E Moriano, $\mathrm{PhD}$ \\
\hline Abstract: & $\begin{array}{l}\text { This work aims at assessing the performances of eight commercial emulsifier } \\
\text { substitutes (not identified as additives) in an artisanal ice cream formulation, in } \\
\text { comparison with the common mono- and di-glycerides of fatty acids (MDG). Besides } \\
\text { the quality features of mixes (density, soluble solids, rheological properties, freezing } \\
\text { point depression) and ice creams (extrusion parameters, overrun, firmness, melting } \\
\text { behavior, shape retention), also the emulsifying activity index (EAI) and creaming } \\
\text { stability (CS) of the considered ingredients were tested. No significant correlations } \\
\text { were found between EAI or CS and quality characteristics of ice creams, confirming the } \\
\text { singular role of MDG in ice cream structuring. Citrus fibers excessively increased the } \\
\text { mix viscosity compared to the reference sample containing MDG ( } 435 \pm 3 \text { vs } 89 \pm 1 \mathrm{mPa} \\
\text { s). Lupine, pea, and rice proteins, as well as citrus fibers significantly improved ice } \\
\text { cream melting behavior ( } 1.60 \pm 0.12 \text { - } 2.33 \pm 0.01 \mathrm{~g} / \text { min melting rate vs. } 2.62 \pm 0.05 \mathrm{~g} / \mathrm{min} \\
\text { of the reference sample). However, at the tested doses there was not a single } \\
\text { ingredient as effective as MDG on ice cream properties. A combination of different } \\
\text { substitutes in different amounts can be a valuable strategy in order to effectively } \\
\text { replace MDG and attain the goal of an ice cream with good quality and clean label. }\end{array}$ \\
\hline
\end{tabular}




\section{UNIVERSITÀ DEGLI STUDI DI MILANO}

Department of Food, Environmental and Nutritional Sciences

Dipartimento di Scienze per gli Alimenti, la Nutrizione e l'Ambiente

Cristina Alamprese

Food Science and Technology

Tel.: +390250319187

Fax: +390250319190

e-mail: cristina.alamprese@unimi.it

Milan, 26 October 2020

Dear Editor,

Please find the second revision of the manuscript "Effects of different emulsifier substitutes on artisanal ice cream quality" by Loffredi E., Moriano M.E., Masseroni L, and Alamprese C. The only Reviewer's suggestion has been followed, dividing Results and Discussion in subsections based on the type of emulsifier substitute. Text changes are highlighted in red.

We do hope that you can appreciate our revision work, thus reconsidering your decision.

The work described has not been published previously, is not under consideration for publication elsewhere, and its publication is approved by all authors and tacitly or explicitly by the responsible authorities where the work was carried out; if accepted, it will not be published elsewhere in the same form, in English or in any other language, including electronically without the written consent of the copyright-holder.

Looking forward to hearing from you soon, I remain sincerely yours.

Cristina Alamprese 


\section{Ms. Ref. No.: LWT-D-20-04443R1}

Effects of different emulsifier substitutes on artisanal ice cream quality Eleonora Loffredi, Maria Eletta Moriano, Letizia Masseroni, Cristina Alamprese

\section{ANSWERS TO REVIEWER\#1}

Although the majority of my minor recommendations were addressed, the organization in the results and discussion was not improved. Again, I think the current organization is insufficient for publication in its current form as it very difficult to follow and hard to understand the treatments that are being compared. As suggested previously, I would recommend discussing each emulsifier separately and comparing them all to the control, but this is just a suggestion. The organization does need to be altered in a significant way though.

The Reviewer's suggestion has been followed, completely re-writing the Results and Discussion section and organizing it in separated paragraphs for each emulsifier. 


\section{Highlights}

- Evaluation of eight commercial emulsifier substitutes for artisanal ice cream

- No correlations between substitutes' emulsifying properties and ice cream quality

- Citrus fibers excessively increased the mix viscosity

- Lupine, pea, rice proteins and citrus fibers improved ice cream melting behavior

- No single ingredient as effective as mono- diglycerides on ice cream properties 
3

4

5

6

7

$8 \quad *$ Corresponding Author. E-mail: cristina.alamprese@ unimi.it; Phone: +39 0250319187; Fax:

$9+3950319190$
Effects of different emulsifier substitutes on artisanal ice cream quality

Eleonora Loffredi, Maria Eletta Moriano, Letizia Masseroni, Cristina Alamprese*

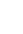

Department of Food, Environmental and Nutritional Sciences (DeFENS), Università degli

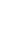
Studi di Milano, via G. Celoria 2, 20133 Milan, Italy

10 


\section{Abstract}

This work aims at assessing the performances of eight commercial emulsifier substitutes (not identified as additives) in an artisanal ice cream formulation, in comparison with the common mono- and di-glycerides of fatty acids (MDG). Besides the quality features of mixes (density, soluble solids, rheological properties, freezing point depression) and ice creams (extrusion parameters, overrun, firmness, melting behavior, shape retention), also the emulsifying activity index (EAI) and creaming stability (CS) of the considered ingredients were tested. No significant correlations were found between EAI or CS and quality characteristics of ice creams, confirming the singular role of MDG in ice cream structuring. Citrus fibers excessively increased the mix apparent viscosity compared to the reference sample containing MDG (435 \pm 3 vs $89 \pm 1 \mathrm{mPa}$ ). Lupine, pea, and rice proteins, as well as citrus fibers significantly improved ice cream melting behavior $(1.60 \pm 0.12-2.33 \pm 0.01 \mathrm{~g} / \mathrm{min}$ melting rate vs. $2.62 \pm 0.05 \mathrm{~g} / \mathrm{min}$ of the reference sample). However, at the tested doses there was not a single ingredient as effective as MDG on ice cream properties. A combination of different substitutes in different amounts can be a valuable strategy in order to effectively replace MDG and attain the goal of an ice cream with good quality and clean label.

Keywords: $\alpha$-cyclodextrin; citrus fibers; phospholipids; legume proteins; rice proteins. 


\section{Introduction}

Ice cream is a frozen dairy product made of a complex matrix of fat clusters, milk solids nonfat, air bubbles, water, sweeteners, and, often, stabilizers, emulsifiers and flavors. Emulsifiers are usually added at a level of $0.1-0.3 \mathrm{~g} / 100 \mathrm{~g}$ and they are of primary importance in enhancing fat destabilization during freezing, favoring partial coalescence between the closest fat globules, so that air bubbles are stabilized with a homogeneous distribution resulting in the desirable ice cream structure and properties. Their fat-destabilization promoting mechanism is linked to the lowering of the fat/water interfacial tension in the mix, which promotes protein displacement from the fat globule surface, thus reducing the stability of the fat globule and allowing partial coalescence during whipping and freezing. The extent of protein displacement from the membrane is a function of the emulsifier type and concentration (Goff \& Hartel, 2013).

The most widely used emulsifiers in ice cream are mono- and di-glycerides of fatty acids (MDG), which are indicated by the code E471 according to the European law about food additives (Reg. EC No 1333/2008). However, nowadays consumers are increasingly demanding "clean label" or "E-free" products, in which no additives indicated with the European E-number are used. Thus, also in the ice cream field, different substitutes have been recently tested for their abilities in conferring to the final product the well-appreciated quality and sensory properties (Levin, Burrington, \& Hartel, 2016b; Ralla et al., 2018), and many ingredients are already available on the market.

A growing interest has been shown for legume proteins, which, as other proteins, can deliver interesting technological functionalities, such as emulsifying properties, because of their ability to be adsorbed at the surface of oil droplets, thus reducing the interfacial tension and preventing coalescence (Karaca, Low, \& Nickerson, 2011). Several studies have demonstrated the emulsifying properties of proteins from lupine (Jayasena, Chih, \& Nasar- 
Abbas, 2010), pea (Tamm, Herbst, Brodkorb, \& Drusch, 2016; Karaca et al., 2011), chickpea, fava beans, lentil, and soy (Karaca et al., 2011), but their use in ice cream needs to be better evaluated. Herald, Aramouni, and Abu-Ghoush (2008) used a soy protein isolate as emulsifying agent alternative to egg yolk in French vanilla ice cream, but the egg-control sample resulted in significantly higher softness and sensory acceptability.

Another category of possible substitutes for ice cream emulsifiers are phospholipids, which can be derived from different sources, such as milk, soy, or rice. Rinaldi et al. (2014) used them in ice cream production and, although the results were not wholly comparable to those of the reference formulation containing MDG in terms of overrun, unfreezable water, and fat destabilization, the authors encouraged further studies about the use of different phospholipids alone or in combination at different levels. Some authors (Bund \& Hartel, 2013; Daw \& Hartel, 2015; Levin et al., 2016b) suggested the use of whey protein concentrate enriched in phospholipids (named pro-cream) and delactosed whey permeate as ice cream ingredients in order to valorize these cheese-making by-products. Actually, emulsifier substitutes can be obtained from correctly treated food by-products or wastes, thus increasing the sustainability of the production chain. In this context, orange fibers recovered from the juice industry were used as fat replacers in ice cream (Crizel, Jablonski, Rios, Rech, \& Flôres, 2013; Crizel, Araujo, Rios, Rech, \& Flôres, 2014), whereas their emulsifying properties were scarcely investigated (Wallecan, McCrae, Debon, Dong, \& Mazoyer, 2015).

Other interesting dietary fibers that can be used as emulsifier alternatives are cyclodextrins, which have a three-dimensional structure with the interior and exterior portions possessing hydrophobic and hydrophilic characteristics. A demonstration of their surface activity can be found in the studies by Davarpanah and Vahabzadeh (2012) and Eslami, Davarpanah, and Vahabzadeh (2017), where the emulsifying functionality of $\beta$-cyclodextrin was evaluated in O/W Pickering emulsions. However, $\alpha$-cyclodextrin emulsifying properties have not been 
deeply studied so far, unless in pharmaceutical preparations (Leclercq \& Nardello-Rataj, 2016).

Despite the high number of emulsifier substitutes present on the market, a comprehensive comparison of different commercial products for artisanal ice cream has not been published so far. Thus, the aim of this work was to assess the performances of eight possible commercial E-free emulsifier substitutes (i.e., whey proteins, whey phospholipids, soy, pea, lupine, and rice proteins, citrus fibers, and $\alpha$-cyclodextrin) in an artisanal ice cream formulation, in comparison to the common MDG. In addition to the mix and ice cream quality features, emulsifying properties (i.e., emulsifying activity index and creaming stability) of the considered ingredients were tested. The final aim is to provide ice cream producers with objective indications about the effects of all these ingredients on ice cream quality, in order to be able to find their way through the ingredient market.

\section{Materials and methods}

\subsection{Ice cream ingredients}

For ice cream production the following liquid and powdered ingredients were used: pasteurized whole milk (Granarolo Alta Qualità, Granarolo S.p.A., Milan, Italy), pasteurized cream (Centrale del Latte di Milano, Milan, Italy), skim milk powder, sucrose, dextrose, stabilizers (a mix of carboxymethylcellulose and tare gum usually used for artisanal ice cream production), and MDG. Powdered ingredients were kindly provided by Comprital S.p.A. (Settala, Italy).

The following commercial ingredients were used as emulsifier substitutes: whey protein concentrate (WPC 75, Lactoland, Dülmen, Germany; protein content, 75 g/100 g; code, WPC); whey protein concentrate with high phospholipid content (Lacprodan MFGM-10, Arla, Viby, Denmark; protein content, >69 g/100 g; phospholipid content, 6-8 g/100 g; code, 
WPP); soy protein isolate (Ipso-CHN, Vaessen-Schoemaker B.V., Deventer, Netherlands; protein content, $90 \mathrm{~g} / 100 \mathrm{~g}$; code, SPI); pea protein concentrate (Pea Protein $80 \%$

Conventional, Barentz Service S.p.A., Paderno Dugnano, Italy; protein content, 81.3 g/100 g; code PPC); lupine protein concentrate (FRALU-CON, Frank Food Products, Twello, Netherlands; protein content, 60 g/100 g; code, LPC); rice protein concentrate (Remypro N80+, Beneo-Remy N.V., Leuven-Wijgmaal, Belgium; protein content, 79 g/100 g; code RPC); citrus fibers (Citri-Fi 100M40; FiberStar, River Falls, WI; code CF); $\alpha$-cyclodextrin (Cavamax W6 Food, Wacker Chemie AG, Munich, Germany; code ACD).

\subsection{Characterization of emulsifier substitutes}

\subsubsection{Protein content}

For protein-based emulsifier substitutes, the protein content was determined according to the AOAC Official Method 920.87 (AOAC, 1999), adopting a nitrogen/protein conversion factor of 6.25 for SPI, PPC, RPC, and LPC, and of 6.38 for WPC and WPP. Results (g/100 g) are expressed as the average and standard deviation values of four replicates.

\subsubsection{Emulsifying activity index}

Emulsifying activity index (EAI) was determined according to the method described by $\mathrm{Mu}$, Zhao, Zhao, Cui, and Liu (2011) with slight modifications. Briefly, for MDG and all the emulsifier substitutes, a $0.5 \mathrm{~g} / 100 \mathrm{~mL}$ solution in $50 \mathrm{mmol} / \mathrm{L}$ sodium phosphate buffer $(\mathrm{pH} 7)$ was prepared. After stirring for $1 \mathrm{~h}$ at $25^{\circ} \mathrm{C}, 6 \mathrm{~mL}$ solution was emulsified with $2 \mathrm{~mL}$ corn oil (Carrefour, Boulogne-Billancourt, France) at $7200 \mathrm{rpm}$ for 5 min using a T25 digital Ultra Turrax (IKA, Staufen, Germany). The obtained emulsion $(200 \mu \mathrm{L})$ was diluted 1:25 in 10 mmol/L sodium phosphate buffer $(\mathrm{pH} 7)$ containing $0.1 \mathrm{~g} / 100 \mathrm{~mL}$ sodium dodecyl sulphate (Sigma Aldrich, Saint Louis, MO). The absorbance was then measured at $500 \mathrm{~nm}$ using a V- 
650 spectrophotometer (Jasco Europe, Cremella, Italy). EAI $\left(\mathrm{m}^{2} / \mathrm{g}\right)$ was calculated by following Equation 1:

$E A I=\frac{2 \cdot 2.303 \cdot A \cdot N}{c \cdot \varphi \cdot l \cdot 10000}$

where $A$ is the absorbance of the diluted emulsion, $N$ is the dilution factor (25), $c$ is the concentration of the tested ingredient in the emulsion $(\mathrm{g} / \mathrm{mL}), \varphi$ is the oil volume fraction of the emulsion $(0.25)$, and $l$ is the path length $(0.01 \mathrm{~m})$. Results are expressed as the average and standard deviation values of four replicates.

\subsubsection{Creaming stability}

Creaming stability (CS) was determined as described by Moriano and Alamprese (2020).

Briefly, Oil Red O (Sigma Aldrich, Saint Louis, MO) was added (0.0015 g/100 g) to corn oil (Carrefour, Boulogne-Billancourt, France). Oil-in-water emulsions (20 mL) were prepared as previously described for EAI measurement, but with a 4:1 ratio water phase:dyed oil. Immediately after preparation, the emulsions were transferred into $10 \mathrm{~mL}$ graduated glass cylinders and stored for $1 \mathrm{~h}$ at $25^{\circ} \mathrm{C}$. The emulsion stability was assessed by measuring the bottom turbid layer separated from the red cream layer. Results are expressed in percentage, as the average and standard deviation values of two measurements.

\subsection{Ice cream formulations}

Ice cream formulations were developed based on a standard artisanal recipe (Table 1). The reference ice cream (REF) was formulated with MDG $(0.3 \mathrm{~g} / 100 \mathrm{~g})$. For the sake of comparison and based on suppliers' suggestions, the emulsifier substitutes were all tested at the same concentration $(1.8 \mathrm{~g} / 100 \mathrm{~g})$, with the exception of WPP $(2.0 \mathrm{~g} / 100 \mathrm{~g})$ and ACD $(0.35$ $\mathrm{g} / 100 \mathrm{~g}$ ) for which different doses were suggested. The different amounts of emulsifying ingredients were balanced in the ice cream mix formulations changing the amounts of whole 
milk and skim milk powder in order to have a constant content of fat $(4.1 \pm 0.1 \mathrm{~g} / 100 \mathrm{~g})$, sugars $(21.0 \pm 0.4 \mathrm{~g} / 100 \mathrm{~g})$, and total solids $(30.7 \pm 0.1 \mathrm{~g} / 100 \mathrm{~g})$. Moreover, in order to better understand the role of emulsifiers on the ice cream properties, a mix formulation with neither MDG nor any emulsifier substitute was developed under the same constraints (named NE).

\subsection{Ice cream production}

Ice cream mixes were prepared as reported in Moriano and Alamprese (2017). Briefly, pasteurization was carried out up to $85^{\circ} \mathrm{C}$ for $1 \mathrm{~min}$ on a $15 \mathrm{~kg}$ batch by using a Pastomaster 60 Tronic (Carpigiani S.r.1, Anzola Emilia, Italy). After 24-hour aging at $4{ }^{\circ} \mathrm{C}$, the mix was frozen with a Labotronic 20-30 batch freezer (Carpigiani S.r.1, Anzola Emilia, Italy), recording extrusion time with a timer. After the product temperature measurement, ice cream samples were packaged and stored for $24 \mathrm{~h}$ at $-30{ }^{\circ} \mathrm{C}$. A conditioning phase at $-16{ }^{\circ} \mathrm{C}$ for $24 \mathrm{~h}$ was carried out before analyses. Two production replicates were carried out for each formulation.

\subsection{Ice cream mix analyses}

After aging, the ice cream mixes of each production were evaluated for density $(\mathrm{g} / \mathrm{mL} ; \mathrm{n}=3)$, soluble solids $\left({ }^{\circ} \mathrm{Bx} ; \mathrm{n}=5\right)$, and rheological behavior $(\mathrm{n}=2)$ as reported by Moriano and Alamprese (2017). Moreover, the theoretical freezing point depression (FPD) was calculated according to Whelan, Vega, Kerry, and Goff (2008), considering technical sheet data of all the ingredients. As for rheological behavior, flow curves were measured at $4{ }^{\circ} \mathrm{C}$ in a $100-500$ $\mathrm{s}^{-1}$ range of shear rate, by using a Physica MCR 300 rheometer (Anton Paar, Graz, Austria) equipped with coaxial cylinders (CC27). Results are expressed in terms of apparent viscosity $(\mathrm{mPa} \cdot \mathrm{s})$ at $290 \mathrm{~s}^{-1}$, consistency coefficient $\mathrm{K}\left(\mathrm{mPa} \cdot \mathrm{s}^{\mathrm{n}}\right)$, and flow behavior index $\mathrm{n}$ (dimensionless). 


\subsection{Ice cream analyses}

183

184

For each production, overrun $(\% ; \mathrm{n}=10)$, firmness $(\mathrm{N} ; \mathrm{n}=20)$, and melting behavior $(\mathrm{n}=3)$ of ice cream samples were determined as reported in Alamprese, Foschino, Rossi, Pompei, and Savani (2002), using $225 \mathrm{~mL}$ samples for overrun and melting and $60 \mathrm{~mL}$ samples for firmness. Briefly, firmness was measured by a penetration test carried out at ambient temperature with a dynamometer (4301, Instron Ltd., High Wycombe, UK) equipped with a $100 \mathrm{~N}$ load cell and a stainless-steel probe ( $8 \mathrm{~mm}$ diameter). Melting behavior was evaluated in a cabinet at $20 \pm 1{ }^{\circ} \mathrm{C}$ for $90 \mathrm{~min}$ and expressed in terms of starting time (min) and rate (g/min), calculated from the linear part of the melting curve. During melting also the ice cream shape retention indexes $R_{t} / R_{0}$ were determined, by applying the image analysis method reported by Moriano and Alamprese (2017). $R_{t} / R_{0}$ (dimensionless) represents the ratio between the height and the width of the ice cream sample $\left(\mathrm{R}_{\mathrm{t}}\right)$ calculated at different times $(15,30,45,60,75,90 \mathrm{~min})$ and referred to the initial ratio $\mathrm{R}_{0}$.

\subsection{Statistical analyses}

One-way analysis of variance (ANOVA) was applied to the analytical data in order to find out significant effects of the emulsifier type. The Least Significant Difference (LSD) test (P < 0.05) was used to calculate significant differences within the average data obtained in the characterization of the emulsifier substitutes, or between properties of an ice cream sample and REF. In this latter case, the results of the two ice cream production replicates carried out for each formulation were compared.

The Pearson product moment correlations between each pair of variables and the relative significance were calculated in order to measure the strength of the linear relationship between the analyzed parameters. 
Statistical analyses were carried out by using the Statgraphics Centurion 18 software (Statgraphics Technology Inc., The Plains, VI).

\section{Results and discussion}

\subsection{Mono- and di-glycerides of fatty acids}

MDG, the most common ice cream emulsifiers, showed the second-best value of EAI after WPP; all the other tested products had significantly lower emulsifying activity (Table 2). This result highlights the ability of MDG in favoring the formation of emulsions. In fact, as explained by Pearce \& Kinsella (1978), EAI is a measure of the interfacial area stabilized per unit weight of emulsifier. However, the ability of MDG in stabilizing emulsions against creaming (CS) was not so high and similar to that of WPC, WPP, and SPI. Indeed, no significant correlation was found between EAI and CS (Table 3). To the best of our knowledge, no other published studies tested EAI and CS of MDG, thus no comparisons can be made.

Due to their surface activity at the air/serum interface (Goff \& Hartel, 2013), MDG were able to increase the air incorporation in REF mix, thus lowering the density with respect to the formulation NE that did not contain any kind of emulsifier (Table 4). The average soluble solid content of all the ice cream mixes was $32.3 \pm 1.6^{\circ} \mathrm{Bx}$, according to the rationale of the recipe development based on keeping constant total solid and sugar contents. Calculation of FPD based on theoretical composition of the different mixes revealed a very similar freezing temperature (ranging from -2.42 to $-2.52{ }^{\circ} \mathrm{C}$ ) for all the samples, according to the constant total solid and sugar content of the developed formulations. The limited amount of the emulsifier substitutes, despite their different salt content (technical sheet data), did not significantly affect FPD, thus assuring soundness of the ice cream quality comparisons. Great differences were observed for the rheological behavior of the mixes. All the samples 
significantly differed from REF for the apparent viscosity, and almost all for $\mathrm{K}$ and $\mathrm{n}$. In particular, the absence of emulsifiers (sample NE) significantly decreased apparent viscosity and $\mathrm{K}$, while increasing $\mathrm{n}$, meaning that the mix was more fluid and less structured than the REF one. This result indicated a mix-structuring effect of MDG, probably related to their already explained surface activity at the air/serum interface, favoring air entrapment.

Moreover, MDG can promote fat nucleation during mix aging, thus structuring fat by partial crystallization (Goff \& Hartel, 2013).

Melting behavior of NE clearly highlighted a specific role of MDG on this ice cream property (Table 5). The presence of MDG made the final product (REF) more resistant to melting, showing a significantly higher starting time $\left(\mathrm{t}_{\mathrm{s}}\right)$ and lower melting rate. Most of the evaluated emulsifier substitutes exerted a similar or even higher effect, demonstrating their suitability in substituting MDG. All the samples well maintained their shape during melting, at least until 60 min (Fig. 1). The slower melting of REF with respect to NE resulted in a higher $R_{t} / R_{0}$ at 75 min, when NE was completed melted.

\subsection{Whey protein concentrate}

WPC had a protein content significantly higher than that of LPC and WPP, but lower than the other protein-based emulsifier substitutes (Table 2). A quite low EAI was observed, meaning a poor ability of WPC to form an emulsion. However, CS of WPC was not significantly different from that of MDG. Apart from RPC, all the protein-based emulsifier substitutes behaved similarly in stabilizing emulsions. This can be related to their water holding capacity, making them thickening agents. In fact, compared to the use of MDG (REF sample), WPC significantly increased apparent viscosity $(+113 \%)$ and $\mathrm{K}(+214 \%)$ of ice cream mix (Table 4), while reducing the flow behavior index (-12\%). The use of a thickening agent is recommended to reduce creaming phenomena in emulsions (McClements, 2016). 
As for ice cream properties, the only significant effect of WPC was on firmness, which increased with respect to REF, despite the similar overrun and FPD value (Table 5). Similar results were found also for SPI_F and PPC_F; further investigations including measurements of fat destabilization will be necessary in order to better understand the effect of these emulsifier substitutes on the ice cream structure.

\subsection{Whey protein concentrate with high phospholipid content}

WPP showed the significantly highest EAI value (Table 2), confirming the high emulsifying capacity of phospholipids from milk globule membranes because of their polar and nonpolar composition reported by Levin, Burrington, and Hartel (2016a). However, it should be noted that the authors, analyzing different types of whey protein phospholipid concentrate, concluded that the functionality of these products may be influenced by several factors, including starting whey composition, processing conditions, and the amount of denatured proteins. An intermediate value of CS was measured for WPP, similar to that of most of the other tested ingredients.

No significant differences were observed between REF and WPP_F mixes, except for a higher value of apparent viscosity (+10 \%) and n (+7\%) when WPP was used (Table 4). WPP_F ice cream showed an overrun significantly lower than that of REF (Table 5). This result was unexpected considering the well-known high foamability of whey proteins (Luck et al., 2013) and the high EAI measured for this ingredient, which should have indicated a high surface activity and a good air bubble dispersion inside the ice cream. However, no significant correlation was found between EAI and overrun (Table 3), confirming the singular role of emulsifiers in the ice cream structuring, linked to fat destabilization rather than the common surface activity important in emulsion formation and stabilization. A possible explanation for the low overrun of WPP_F is the presence of the high amount of fat in WPP, which can 
disrupt the viscoelastic protein layer at the air/serum interfaces by reducing the proteinprotein interactions necessary for air bubble stabilization (Levin et al., 2016a). After 90 min of melting, only five samples out ten were uncompleted melted; among these, WPP_F showed the best shape retention index (>0.65), together with LPC_F.

\subsection{Soy protein isolate}

SPI had the significantly highest value of protein content, because it was the only protein isolate (Table 2). All the other protein-based substitutes were protein concentrates obtained from different sources. However, SPI did not show the highest EAI and CS values. In fact, no significant correlations were found between protein content and EAI or CS (Table 3), highlighting the importance of the protein type and quality over the amount. The possible presence of other surface-active components in the ingredients and the production method could also have affected this result. For instance, Karaca et al. (2011) reported similar emulsifying activities for soy protein and pea protein isolates produced in the same way, while in this study SPI and PPC showed significantly different EAI values, being an isolate and a concentrate, respectively, obtained from two different suppliers.

With respect to MDG, the use of SPI imparted a significantly higher apparent viscosity (+43 $\%)$ and consistency coefficient (+152\%) to the ice cream mix (Table 4), while decreasing the flow behavior index (-12\%). This resulted in a significantly shorter extrusion time and higher extrusion temperature (Table 5). Actually, significant correlations were found between these variables (Table 3). Extrusion time is linked to the initial consistency of the mix because it is signaled by the freezer when a given energy input is required to maintain a constant speed of the internal dasher. Thus, if a more viscous mix is loaded in the freezer, it will take a shorter time to reach the consistency necessary for the extrusion, and the final product will have a 
higher temperature. As already stated, the higher firmness of SPI_F ice cream with respect to

306 REF needs for further investigations.

307

308

309

310

311

312

313

314

315

316

317

318

319

320

321

322

323

324

325

326

327

328

\subsection{Pea protein concentrate}

PPC showed an EAI significantly lower than that of MDG (-49\%), but a higher CS (+5\%) (Table 2).

Similarly to the other protein-based emulsifier substitutes, PPC significantly affected the ice cream mix rheological behavior compared to MDG (Table 4), with an increase in apparent viscosity and $\mathrm{K}(+37 \%$ and $+501 \%$, respectively), and a decrease in $\mathrm{n}(-36 \%)$.

PPC_F ice cream showed a firmness significantly higher than that of REF (+207\%), with a lower melting rate $(-11 \%)$ (Table 5). In this case too, further investigations are needed to better understand the real role of PPC on ice cream structure.

\subsection{Lupine protein concentrate}

LPC showed the significantly lowest protein content, coupled with the lowest value of EAI (Table 2).

LPC_F mix had a significantly lower density with respect to REF (Table 4), possibly due to the good foaming capacity of the protein concentrate used, which can favor air incorporation when ice cream mix is stirred during pasteurization, cooling, and, to a lesser extent, aging. According to Pozani, Doxastakis, and Kiosseoglou (2002), foaming properties of lupine proteins may improve or deteriorate as a result of the heat treatment applied during production, depending on molecular unfolding or aggregation.

Like most of the other emulsifier substitutes, LPC significantly increased apparent viscosity $(+77 \%)$ and $\mathrm{K}(+124 \%)$ of the mix with respect to the use of MDG (Table 4). 
The LPC_F ice cream showed an overrun significantly lower than that of REF (Table 5).

330 However, the low overrun could be only apparent due to the low mix density value (used in 331 the calculation of overrun). Actually, considering the same density of REF, the overrun of

332 LPC_F would have been $49.2 \pm 3.6 \%$, not significantly different from the REF one. The use

333 of LPC significantly increased $t_{s}$ and decreased melting rate with respect to REF, also

334 conferring the best shape retention index ( $\geq 0.65)$, like WPP (Fig. 1).

\subsection{Rice protein concentrate}

RPC showed the best emulsifying capacity among the plant protein-based ingredients and the highest CS (Table 2). This is in contrast with the results by Zhao, Shen, Wu, Zhang, and Xu (2020), who reported a very low EAI for rice proteins in comparison with soybean and pea proteins, probably due to the very low solubility of their rice protein concentrate at $\mathrm{pH}$ 7. In fact, Mun, Shin, and Kim (2016) demonstrated that solubility of rice proteins depends on the

342 rice cultivar used for the extraction and emulsifying properties are affected not only by

343 protein solubility but also by other properties, such as the amino acid composition and the hydrophilic-lipophilic balance.

RPC_F mix showed a density value significantly higher than that of REF (Table 4). Thus, it is presumable that the used rice proteins had low foaming capacity, as observed also by Zhao et al. (2020) for a different commercial product, resulting in a denser ice cream mix. The significantly lower value of Brix degree was probably due to the interference of some RPC components during the analysis with the digital refractometer. The increase in apparent viscosity (+19\%) and K (+446\%) was coupled with the highest decrease in n (-40\%). with the use of RPC instead of MDG (Table 5). 


\subsection{Citrus fibers}

CF showed EAI values significantly higher than those of the legume protein-based ingredients, but lower than that of MDG (Table 2). CF surface properties are mainly linked to protein residues within the pectin and their covalent bonding (Wallecan et al., 2015).

Emulsion stabilizing properties of CF were very low, resulting in the significantly lowest CS value, despite the high water retention capacity of orange pulp fiber found in a previous work by Wallecan et al. (2015), ascribed to cellulose and ensuring the thickening of the water phase. As demonstrated by Chatsisvili, Amvrosiadis, and Kiosseoglou (2012), it is possible that the progressive water absorption by pulp particles during emulsion storage forced the oil droplets to interact more intensively, compressing against each other and thus enhancing the possibility to coalesce.

Like RPC_F, also CF_F showed significantly lower values of soluble solid content with respect to REF (Table 4), probably due to interferences during the measurement. The use of CF resulted in extremely high values of apparent viscosity and $\mathrm{K}$, which impaired a good management of the mix, due to difficulties in pouring the sample, and affected freezing behavior. In fact, CF_F showed the significantly lowest extrusion time and highest extrusion temperature (Table 5). These results are related to the high water holding capacity of CF. As a consequence, $\mathrm{CF} \_$F ice cream showed an overrun significantly lower than that of REF. Besides the lower whipping time in the freezer, the very high apparent viscosity of the mix could have also decreased the mix whipping rate due to difficulties in air penetration (Goff \& Hartel, 2013). A significant effect of the high water-retention of CF was observed also on the ice cream melting behavior. CF_F showed the highest $t_{\mathrm{s}}$ and the lowest melting rate values. Indeed, mix apparent viscosity and $\mathrm{K}$ resulted to be highly correlated $(\mathrm{P}<0.001)$ with both $\mathrm{t}_{\mathrm{s}}$ and rate (Table 3) as reported also by Wu, Freire, and Hartel (2019). However, during melting 
CF_F showed the worst retention indexes (Fig. 1), even if a significant difference compared to REF was observed only at $30 \mathrm{~min}$.

\section{9. $\alpha$-cyclodextrin}

ACD showed an EAI significantly higher than those of the legume protein-based ingredients, but lower than that of MDG (Table 2). Its emulsifying properties are linked to the peculiar molecular structure: $\alpha$-cyclodextrin is a cyclic oligosaccharide composed of six $\alpha-D-$ glucopyranose units resulting in a shallow truncated cone shape with a hydrophilic annulus and a largely hydrophobic cavity (Leclercq \& Nardello-Rataj, 2016). CS value of ACD was the second best among all the emulsifier substitutes. These good properties of ACD could be ascribed to the formation of a highly stable Pickering emulsion, as already reported by Leclercq and Nardello-Rataj (2016) who demonstrated the ability of cyclodextrin to selfassemble into colloidal particles, partially wettable by water and oil.

Contrarily to most of the studied emulsifier substitutes, the use of ACD significantly decreased apparent viscosity $(-34 \%)$ and $\mathrm{K}(-47 \%)$, while increasing $\mathrm{n}(+7 \%)$, meaning that the mix was more fluid and less structured than the REF one (Table 4).

No significant effects of ACD on ice cream characteristics were observed (Table 5, Fig. 1), meaning that the use of $\alpha$-cyclodextrin allowed the production of a final product with the same quality of REF.

\section{Conclusions}

The study evaluated different commercial ingredients that can be used as MDG substitutes in ice cream formulation, highlighting their different properties. In particular, results showed that the beneficial effects of MDG in ice cream are mainly related to an increase in mix viscosity and a slowdown of ice cream melting behavior. Apart from $\alpha$-cyclodextrin, all the 
other tested ingredients increased the mix apparent viscosity and K, giving sometimes too high values not compatible with a proper behavior of the mixes in the production plant (sample CF_F). All the emulsifier substitutes resulted in good melting properties of ice creams, comparable with those of REF or even better. In particular, LPC and CF improved both the melting rate and starting time, whereas PPC and RPC had a significant effect only on the rate. However, it is important to underline that the source and process conditions of the different substitutes can affect their technological properties. Thus, the results of this work can provide a first guide for ice cream producers, but a careful evaluation of the several products present on the market is absolutely necessary in order to make a correct choice and a proper balance of the ice cream formulation.

In conclusion, the study demonstrated that at the tested doses there was not a single ingredient that could be considered as effective as MDG on ice cream properties. Probably a combination of different substitutes in different amounts can be a valuable strategy in order to effectively substitute MDG and attain the goal of an ice cream with good quality and clean label. In this perspective, a Design of Experiment approach to the study of different substitutes' mixing can be a valid tool for an efficient optimization of the ice cream formulation.

\section{Acknowledgements}

The Authors wish to thank Alvena s.r.l. (San Giuliano M.se, Milan, Italy), Prodotti Gianni s.r.l. (Milan, Italy), and IMCD Italia S.p.A. (Milan, Italy) for kindly providing some of the emulsion substitutes.

\section{Funding sources}

This work was supported by Unione Italiana Food (UIF) - “Gelato Ingredients Group”. 


\section{References}

430 Alamprese C., Foschino R., Rossi M., Pompei C., \& Savani L. (2002). Survival of

Lactobacillus johnsonii La1 and influence of its addition in retail-manufactured ice cream produced with different sugar and fat concentration. International Dairy Journal, 12, 201-208.

AOAC. (1999). Official methods of analysis (16th ed.). Gaithersburg: Association of Official Analytical Chemists.

Bund, R. K., \& Hartel, R. W. (2013). Blends of delactosed permeate and pro-cream in ice cream: Effects on physical, textural and sensory attributes. International Dairy Journal, 31, 132-138.

Chatsisvili, N. T., Amvrosiadis, I., \& Kiosseoglou, V. (2012). Physicochemical properties of a dressing-type o/w emulsion as influenced by orange pulp fiber incorporation. $L W T$ Food Science and Technology, 46, 335-340.

Crizel, T. M., Araujo, R. R., Rios, A. O., Rech, R., \& Flôres, S. H. (2014). Orange fiber as a novel fat replacer in lemon ice cream. Food Science and Technology (Campinas), 34, 332-340.

Crizel, T. M., Jablonski, A., Rios, A. O., Rech, R., \& Flôres, S. H. (2013). Dietary fiber from orange byproducts as a potential fat replacer. LWT - Food Science and Technology, 53, $9-14$.

Davarpanah, L., \& Vahabzadeh, F. (2012). Formation of oil-in-water (O/W) pickering emulsions via complexation between $\beta$-cyclodextrin and selected organic solvents. Starch/Stärke, 64, 898-913.

Daw, E., \& Hartel, R. W. (2015). Fat destabilization and melt-down of ice creams with increased protein content. International Dairy Journal, 43, 33-41. 
Eslami, P., Davarpanah, L., \& Vahabzadeh, F. (2017). Encapsulating role of $\beta$-cyclodextrin in formation of pickering water-in-oil-in-water $\left(\mathrm{W}_{1} / \mathrm{O} / \mathrm{W}_{2}\right)$ double emulsions containing Lactobacillus dellbrueckii. Food Hydrocolloids, 64, 133-148.

Goff, H. D., \& Hartel, R. W. (2013). Ice cream (7th ed.). New York: Springer.

Herald, T. J., Aramouni, F. M., \& Abu-Ghoush, M. H. (2008). Comparison study of egg yolks and egg alternatives in french vanilla ice cream. Journal of Texture Studies, 39, 284-295.

Jayasena, V., Chih, H. J., \& Nasar-Abbas, S. M. (2010). Functional properties of sweet lupin protein isolated and tested at various $\mathrm{pH}$ levels. Research Journal of Agriculture and Biological Sciences, 6, 130-137.

Karaca, A. C., Low, N., \& Nickerson, M. (2011). Emulsifying properties of chickpea, faba bean, lentil and pea proteins produced by isoelectric precipitation and salt extraction. Food Research International, 44, 2742-2750.

Leclercq, L., \& Nardello-Rataj, V. (2016). Pickering emulsions based on cyclodextrins: A smart solution for antifungal azole derivatives topical delivery. European Journal of Pharmaceutical Sciences, 82, 126-137.

Levin, M. A., Burrington, K. J., \& Hartel, R. W. (2016a). Composition and functionality of whey protein phospholipid concentrate and delactosed permeate. Journal of Dairy Science, 99, 6937-6947.

Levin, M. A., Burrington, K. J., \& Hartel, R. W. (2016b). Whey protein phospholipid concentrate and delactosed permeate: Applications in caramel, ice cream, and cake. Journal of Dairy Science, 99, 6948-6960.

Luck, P. J., Vardhanabhuti, B., Yong, Y. H., Laundon, T., Barbano, D. M., \& Foegeding, E. A. (2013). Comparison of functional properties of $34 \%$ and $80 \%$ whey protein and milk serum protein concentrates. Journal of Dairy Science, 96, 5522-5531.

McClements, D. J. (2016). Food emulsions. Principles, practices, and techniques (3rd ed.). 
479

480

481

482

483

484

485

486

487

488

489

490

491

492

493

494

495

496

497

498

499

500

501

502

Moriano, M. E., \& Alamprese C. (2017). Honey, trehalose and erythritol as sucrosealternative sweeteners for artisanal ice cream. A pilot study. LWT - Food Science and Technology, 75, 329-334.

Moriano M. E., \& Alamprese C. (2020). Whey protein concentrate and egg white powder as structuring agents of double emulsions for food applications. Food and Bioprocess Technology, 13, 1154-1165.

Mu, L., Zhao, H., Zhao, M., Cui, C., \& Liu, L. (2011). Physicochemical properties of soy protein isolates-acacia gum conjugates. Czech Journal of Food Science, 29, 129-136.

Mun, S., Shin, M., \& Kim, Y. R. (2016). Emulsifying properties of proteins isolated from various rice cultivars. Food and Bioprocess Technology, 9, 813-821.

Pearce, K. N. \& Kinsella, J. E. (1978). Emulsifying properties of proteins: Evaluation of a turbidimetric technique. Journal of Agricultural and Food Chemistry, 26, 716-723.

Pozani, S., Doxastakis,G., \& Kiosseoglou, V. (2002). Functionality of lupin seed protein isolate in relation to its interfacial behaviour. Food Hydrocolloids, 16, 241-247.

Ralla, T., Salminen, H., Edelmann, M., Dawid, C., Hofmann, T., \& Weiss, J. (2018). Oat bran extract (Avena sativa L.) from food by-product streams as new natural emulsifier. Food Hydrocolloids, 81, 253-262.

Reg. (EC) No 1333/2008 of the European Parliament and of the Council of 16 December 2008 on food additives. Official Journal of the European Union, L 354, 16-33.

Rinaldi, M., Dall'Asta, C., Paciulli, M., Guizzetti, S., Barbanti, D., \& Chiavaro, E. (2014). Innovation in the Italian ice cream production: effect of different phospholipid emulsifiers. Dairy Science \& Technology, 94, 33-49.

Tamm, F., Herbst, S., Brodkorb, A., \& Drusch, S. (2016). Functional properties of pea protein hydrolysates in emulsions and spray-dried microcapsules. Food Hydrocolloids, 58, 204- 
504 Wallecan, J., McCrae, C., Debon, S. J. J., Dong, J., \& Mazoyer, J. (2015). Emulsifying and stabilizing properties of functionalized orange pulp fibers. Food Hydrocolloids, 47, 115123.

Whelan, A. P., Vega, C., Kerry, J. P., \& Goff, H. D. (2008). Physicochemical and sensory optimisation of a low glycemic index ice cream formulation. International Journal of Food Science and Technology, 43, 1520-1527.

Wu, B., Freire, D. O., \& Hartel, R. W. (2019). The effect of overrun, fat destabilization, and ice cream mix viscosity on entire meltdown behavior. Journal of Food Science, 84, $2562-2571$.

Zhao, H., Shen, C., Wu, Z., Zhang, Z., \& Xu, C. (2020). Comparison of wheat, soybean, rice, and pea protein properties for effective applications in food products. Journal of Food Biochemistry, 44, 13157.

516 
517 Figure legends

518 Fig. 1. Shape retention index $\left(\mathrm{R}_{t} / \mathrm{R}_{0}\right)$ of the ice cream samples as a function of melting time;

519

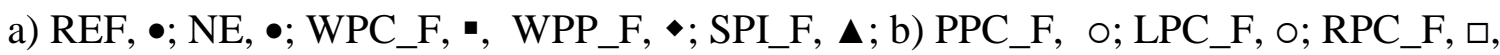

520 CF_F, $\diamond ; A C D \_F, \triangle$. Error bars represent standard deviation values of two production

521 replicates. REF: reference ice cream formulation containing mono- and di-glycerides of fatty

522 acids; NE: ice cream formulation without emulsifiers; WPC_F, ice cream formulation with

523 whey protein concentrate; WPP_F, ice cream formulation with whey protein concentrate at

524 high phospholipid content; SPI_F, ice cream formulation with soy protein isolate; PPC_F, ice

525 cream formulation with pea protein concentrate; LPC_F, ice cream formulation with lupine

526 protein concentrate; RPC_F, ice cream formulation with rice protein concentrate; CF_F, ice

527 cream formulation with citrus fibers; ACD_F, ice cream formulation with $\beta$-cyclodextrin. 
Table 1. Formulation $(\mathrm{g} / 100 \mathrm{~g})$ of the ice cream samples prepared to study the effect of different commercial emulsifier substitutes.

\begin{tabular}{|c|c|c|c|c|c|c|c|c|c|c|}
\hline \multirow[b]{2}{*}{ Ingredient } & \multicolumn{10}{|c|}{ Ice cream samples } \\
\hline & REF & $\mathrm{NE}$ & WPC_F & WPP_F & SPI_F & PPC_F & LPC_F & RPC_F & CF_F & ACD_F \\
\hline Pasteurized whole milk & 76.0 & 76.3 & 76.3 & 76.7 & 76.3 & 76.3 & 76.3 & 76.3 & 76.3 & 76.55 \\
\hline Pasteurized milk cream & 3.1 & 3.1 & 3.1 & 3.1 & 3.1 & 3.1 & 3.1 & 3.1 & 3.1 & 3.1 \\
\hline Skim milk powder & 5.4 & 5.4 & 3.6 & 3.0 & 3.6 & 3.6 & 3.6 & 3.6 & 3.6 & 4.8 \\
\hline Sucrose & 12.0 & 12.0 & 12.0 & 12.0 & 12.0 & 12.0 & 12.0 & 12.0 & 12.0 & 12.0 \\
\hline Dextrose & 3.0 & 3.0 & 3.0 & 3.0 & 3.0 & 3.0 & 3.0 & 3.0 & 3.0 & 3.0 \\
\hline Stabilizers & 0.2 & 0.2 & 0.2 & 0.2 & 0.2 & 0.2 & 0.2 & 0.2 & 0.2 & 0.2 \\
\hline MDG & 0.3 & - & - & - & - & - & - & - & - & - \\
\hline WPC & - & - & 1.8 & - & - & - & - & - & - & - \\
\hline WPP & - & - & - & 2.0 & - & - & - & - & - & - \\
\hline SPI & - & - & - & - & 1.8 & - & - & - & - & - \\
\hline PPC & - & - & - & - & - & 1.8 & - & - & - & - \\
\hline LPC & - & - & - & - & - & - & 1.8 & - & - & - \\
\hline RPC & - & - & - & - & - & - & - & 1.8 & - & - \\
\hline $\mathrm{CF}$ & - & - & - & - & - & - & - & - & 1.8 & - \\
\hline $\mathrm{ACD}$ & - & - & - & - & - & - & - & - & - & 0.35 \\
\hline
\end{tabular}

MDG, mono- and di-glycerides of fatty acids; WPC, whey protein concentrate; WPP, whey protein concentrate with high phospholipid content; SPI, soy protein isolate; PPC, pea protein concentrate; LPC, lupine protein concentrate; RPC, rice protein concentrate; $\mathrm{CF}$, citrus fibers; ACD, $\alpha$ cyclodextrin. 
Table 2. Values (mean \pm standard deviation) of protein content, emulsifying activity index (EAI) and creaming stability (CS) of mono- and di-glycerides of fatty acids and ingredients used as emulsifier substitutes in ice cream formulation.

\begin{tabular}{llll}
\hline Sample & Protein $(\mathrm{g} / 100 \mathrm{~g})$ & EAI $\left(\mathrm{m}^{2} / \mathrm{g}\right)$ & CS $(\%)$ \\
\hline MDG & n.d. & $311 \pm 4^{\mathrm{h}}$ & $69.5 \pm 1.0^{\mathrm{b}}$ \\
WPC & $74.1 \pm 0.8^{\mathrm{c}}$ & $140 \pm 3^{\mathrm{b}}$ & $71.7 \pm 0.4^{\mathrm{bc}}$ \\
WPP & $66.6 \pm 1.1^{\mathrm{b}}$ & $430 \pm 9^{\mathrm{i}}$ & $72.0 \pm 0.1^{\mathrm{bc}}$ \\
SPI & $89.3 \pm 1.7^{\mathrm{e}}$ & $172 \pm 1^{\mathrm{d}}$ & $71.3 \pm 1.5^{\mathrm{bc}}$ \\
PPC & $77.8 \pm 0.4^{\mathrm{d}}$ & $157 \pm 3^{\mathrm{c}}$ & $73.0 \pm 1.4^{\mathrm{c}}$ \\
LPC & $59.2 \pm 0.3^{\mathrm{a}}$ & $107 \pm 1^{\mathrm{a}}$ & $72.5 \pm 1.4^{\mathrm{c}}$ \\
RPC & $77.2 \pm 1.4^{\mathrm{d}}$ & $246 \pm 7^{\mathrm{g}}$ & $82.5 \pm 1.2^{\mathrm{e}}$ \\
CF & n.d. & $210 \pm 3^{\mathrm{e}}$ & $62.2 \pm 1.4^{\mathrm{a}}$ \\
ACD & n.d. & $220 \pm 5^{\mathrm{f}}$ & $79.4 \pm 0.3^{\mathrm{d}}$ \\
\hline
\end{tabular}

MDG, mono- and di-glycerides of fatty acids; WPC, whey protein concentrate; WPP, whey protein concentrate with high phospholipid content; SPI, soy protein isolate; PPC, pea protein concentrate; LPC, lupine protein concentrate; RPC, rice protein concentrate; $\mathrm{CF}$, citrus fibers; ACD, $\alpha$-cyclodextrin.

${ }^{\mathrm{a}-\mathrm{i}}$, mean values in each column followed by different letters were significantly different $(\mathrm{P}<$ $0.05)$.

n.d., not determined. 
Table 3. Pearson product moments correlation between each pair of variables tested on emulsifier substitutes, ice cream mixes and final ice creams. Significant moments $(\mathrm{P}<0.05)$ are highlighted in bold.

\begin{tabular}{|c|c|c|c|c|c|c|c|c|c|c|c|c|c|c|c|}
\hline & Protein & EAI & $\mathrm{CS}$ & Density & Sol. solids & FPD & Viscosity & $\mathrm{K}$ & $\mathrm{n}$ & Extr. time & Extr. temp. & Overrun & Firmness & ts & Rate \\
\hline Protein & 1.000 & & & & & & & & & & & & & & \\
\hline EAI & -0.123 & 1.000 & & & & & & & & & & & & & \\
\hline $\mathrm{CS}$ & 0.053 & 0.018 & 1.000 & & & & & & & & & & & & \\
\hline Density & 0.634 & 0.512 & 0.428 & 1.000 & & & & & & & & & & & \\
\hline Sol. solids & 0.245 & -0.194 & -0.345 & -0.026 & 1.000 & & & & & & & & & & \\
\hline FPD & -0.169 & 0.121 & 0.137 & -0.106 & -0.363 & 1.000 & & & & & & & & & \\
\hline Viscosity & -0.165 & -0.246 & -0.739 & -0.494 & -0.277 & 0.241 & 1.000 & & & & & & & & \\
\hline $\mathrm{K}$ & 0.365 & -0.276 & -0.443 & -0.301 & -0.430 & 0.324 & 0.860 & 1.000 & & & & & & & \\
\hline $\mathrm{n}$ & -0.459 & 0.395 & -0.144 & 0.060 & 0.245 & -0.398 & -0.320 & -0.708 & 1.000 & & & & & & \\
\hline Extr. time & -0.421 & 0.276 & 0.643 & 0.399 & 0.072 & -0.463 & -0.777 & -0.767 & 0.420 & 1.000 & & & & & \\
\hline Extr. temp. & 0.283 & 0.023 & -0.674 & -0.282 & -0.131 & 0.454 & 0.688 & 0.585 & -0.122 & -0.916 & 1.000 & & & & \\
\hline Overrun & 0.800 & 0.200 & 0.410 & 0.814 & 0.293 & -0.188 & -0.489 & -0.210 & -0.266 & 0.350 & -0.418 & 1.000 & & & \\
\hline Firmness & 0.648 & -0.354 & -0.181 & 0.039 & 0.436 & 0.246 & -0.034 & 0.074 & -0.276 & -0.475 & 0.418 & 0.155 & 1.000 & & \\
\hline$t_{s}$ & -0.657 & -0.082 & -0.665 & -0.448 & -0.498 & 0.285 & 0.933 & 0.819 & -0.214 & -0.754 & 0.765 & -0.611 & -0.065 & 1.000 & \\
\hline Rate & 0.169 & 0.241 & 0.545 & 0.519 & 0.492 & -0.358 & -0.918 & -0.943 & 0.529 & 0.779 & -0.668 & 0.494 & 0.026 & -0.927 & 1.000 \\
\hline
\end{tabular}

EAI, emulsifying activity index; CS, creaming stability; Sol. solids, soluble solids; FPD, theoretical freezing point depression; K, consistency coefficient; $n$, flow behavior index; Extr. time, extrusion time; Extr. temp., extrusion temperature; $\mathrm{t}_{\mathrm{s}}$, starting time of melting; Rate, melting rate. 
Table 4. Properties of ice cream mixes (mean \pm s.d. values of two technological replicates) produced with different types of emulsifier substitutes.

\begin{tabular}{lllllll}
\hline Sample & $\begin{array}{l}\text { Density } \\
(\mathrm{g} / \mathrm{mL})\end{array}$ & $\begin{array}{l}\text { Soluble solids } \\
\left({ }^{\circ} \mathrm{Bx}\right)\end{array}$ & $\begin{array}{l}\text { FPD } \\
\left({ }^{\circ} \mathrm{C}\right)\end{array}$ & $\begin{array}{l}\text { Apparent viscosity } \\
(\mathrm{mPa} \mathrm{s})\end{array}$ & $\begin{array}{l}\mathrm{K} \\
\left(\mathrm{mPa} \mathrm{s}^{\mathrm{n}}\right)\end{array}$ & $\mathrm{n}(-)$ \\
\hline REF & $1.02 \pm 0.01$ & $33.8 \pm 0.1$ & -2.49 & $89 \pm 1$ & $575 \pm 40$ & $0.659 \pm 0.006$ \\
NE & $1.10 \pm 0.01^{*}$ & $33.9 \pm 1.7$ & -2.48 & $59 \pm 1^{*}$ & $348 \pm 24^{*}$ & $0.697 \pm 0.001^{*}$ \\
WPC_F & $1.03 \pm 0.01$ & $33.5 \pm 1.6$ & -2.39 & $190 \pm 4^{*}$ & $1810 \pm 432^{*}$ & $0.570 \pm 0.092^{*}$ \\
WPP_F & $1.07 \pm 0.05$ & $31.9 \pm 2.1$ & -2.33 & $98 \pm 3^{*}$ & $472 \pm 6$ & $0.718 \pm 0.003^{*}$ \\
SPI_F & $1.04 \pm 0.03$ & $33.9 \pm 0.9$ & -2.39 & $128 \pm 5^{*}$ & $1453 \pm 12^{*}$ & $0.573 \pm 0.007^{*}$ \\
PPC_F & $1.03 \pm 0.01$ & $32.7 \pm 0.4$ & -2.39 & $122 \pm 4^{*}$ & $3458 \pm 671^{*}$ & $0.410 \pm 0.045^{*}$ \\
LPC_F & $0.83 \pm 0.03^{*}$ & $32.8 \pm 1.4$ & -2.40 & $158 \pm 8^{*}$ & $1290 \pm 133^{*}$ & $0.634 \pm 0.023$ \\
RPC_F & $1.07 \pm 0.01^{*}$ & $30.2 \pm 1.0 *$ & -2.36 & $106 \pm 5^{*}$ & $3141 \pm 386^{*}$ & $0.386 \pm 0.009^{*}$ \\
CF_F & $0.95 \pm 0.03$ & $30.5 \pm 0.1^{*}$ & -2.40 & $435 \pm 3^{*}$ & $6609 \pm 198^{*}$ & $0.520 \pm 0.007^{*}$ \\
ACD_F & $1.07 \pm 0.06$ & $30.1 \pm 1.3$ & -2.44 & $58 \pm 4^{*}$ & $300 \pm 16^{*}$ & $0.711 \pm 0.003^{*}$ \\
\hline
\end{tabular}

FPD, theoretical freezing point depression; $\mathrm{K}$, consistency coefficient; $\mathrm{n}$, flow behavior index.

REF: reference ice cream formulation containing mono- and di-glycerides of fatty acids; NE: ice cream formulation without emulsifiers; WPC_F, ice cream formulation with whey protein concentrate; WPP_F, ice cream formulation with whey protein concentrate at high phospholipid content; SPI_F, ice cream formulation with soy protein isolate; PPC_F, ice cream formulation with pea protein concentrate; LPC_F, ice cream formulation with lupine protein concentrate; RPC_F, ice cream formulation with rice protein concentrate; $C F \_F$, ice cream formulation with citrus fibers;

ACD_F, ice cream formulation with $\alpha$-cyclodextrin.

* Result significantly different $(\mathrm{P}<0.05)$ from the reference $(\mathrm{REF})$. 
Table 5. Extrusion parameters and physical properties of ice cream samples (mean \pm s.d. values of two technological replicates).

\begin{tabular}{lllllll}
\hline Sample & \multirow{2}{*}{$\begin{array}{l}\text { Extrusion time } \\
(\mathrm{min})\end{array}$} & $\begin{array}{l}\text { Extrusion } \\
\text { temperature } \\
\left({ }^{\circ} \mathrm{C}\right)\end{array}$ & Overrun $(\%)$ & Firmness $(\mathrm{N})$ & \multicolumn{2}{c}{ Melting behavior } \\
\cline { 5 - 6 } & & $-8.1 \pm 0.3$ & $50.8 \pm 0.4$ & $17.7 \pm 1.9$ & $16.9 \pm 0.9$ & $2.62 \pm 0.05$ \\
\hline REF & $7.3 \pm 0.1$ & $-7.8 \pm 0.2$ & $58.5 \pm 0.9$ & $21.5 \pm 1.8$ & $13.4 \pm 0.7^{*}$ & $2.81 \pm 0.02^{*}$ \\
NE & $6.9 \pm 0.3$ & $-7.9 \pm 0.1$ & $49.9 \pm 0.4$ & $28.8 \pm 0.2^{*}$ & $20.2 \pm 2.5$ & $2.53 \pm 0.19$ \\
WPC_F & $6.8 \pm 0.3$ & $-6.8 \pm 0.4$ & $41.6 \pm 0.9^{*}$ & $25.1 \pm 3.7$ & $23.1 \pm 2.4$ & $2.58 \pm 0.01$ \\
WPP_F & $6.6 \pm 0.1^{*}$ & $-6.8 \pm 0.9$ & rate $(\mathrm{g} / \mathrm{min})$ \\
SPI_F & $6.1 \pm 0.2^{*}$ & $-6.5 \pm 0.2^{*}$ & $52.0 \pm 1.4$ & $57.2 \pm 0.8^{*}$ & $21.0 \pm 1.7$ & $2.51 \pm 0.05$ \\
PPC_F & $6.2 \pm 0.5$ & $-7.2 \pm 0.5$ & $50.6 \pm 1.9$ & $54.4 \pm 3.3^{*}$ & $21.8 \pm 1.1$ & $2.33 \pm 0.01^{*}$ \\
LPC_F & $6.5 \pm 0.2$ & $-7.4 \pm 0.1$ & $21.6 \pm 0.8^{*}$ & $23.1 \pm 2.8$ & $24.0 \pm 0.5^{*}$ & $2.33 \pm 0.01^{*}$ \\
RPC_F & $6.9 \pm 0.2$ & $-8.0 \pm 0.1$ & $59.2 \pm 0.2$ & $12.3 \pm 1.1$ & $19.1 \pm 1.3$ & $2.32 \pm 0.03^{*}$ \\
CF_F & $5.5 \pm 0.1^{*}$ & $-5.9 \pm 0.1^{*}$ & $30.3 \pm 0.8^{*}$ & $21.3 \pm 0.5$ & $50.8 \pm 1.0^{*}$ & $1.60 \pm 0.12^{*}$ \\
ACD_F & $7.3 \pm 0.1$ & $-7.9 \pm 0.1$ & $38.5 \pm 4.8$ & $20.3 \pm 4.6$ & $22.1 \pm 2.2$ & $2.63 \pm 0.04$ \\
\hline Of
\end{tabular}

$\mathrm{t}_{\mathrm{s}}$, starting time of melting

REF: reference ice cream formulation containing mono- and di-glycerides of fatty acids; NE: ice cream formulation without emulsifiers;

WPC_F, ice cream formulation with whey protein concentrate; WPP_F, ice cream formulation with whey protein concentrate at high

phospholipid content; SPI_F, ice cream formulation with soy protein isolate; PPC_F, ice cream formulation with pea protein concentrate;

LPC_F, ice cream formulation with lupine protein concentrate; RPC_F, ice cream formulation with rice protein concentrate; $C F \_F$, ice cream formulation with citrus fibers; ACD_F, ice cream formulation with $\alpha$-cyclodextrin.

* Result significantly different $(\mathrm{P}<0.05)$ from the reference $(\mathrm{REF})$. 
Figure 1

Figure 1.
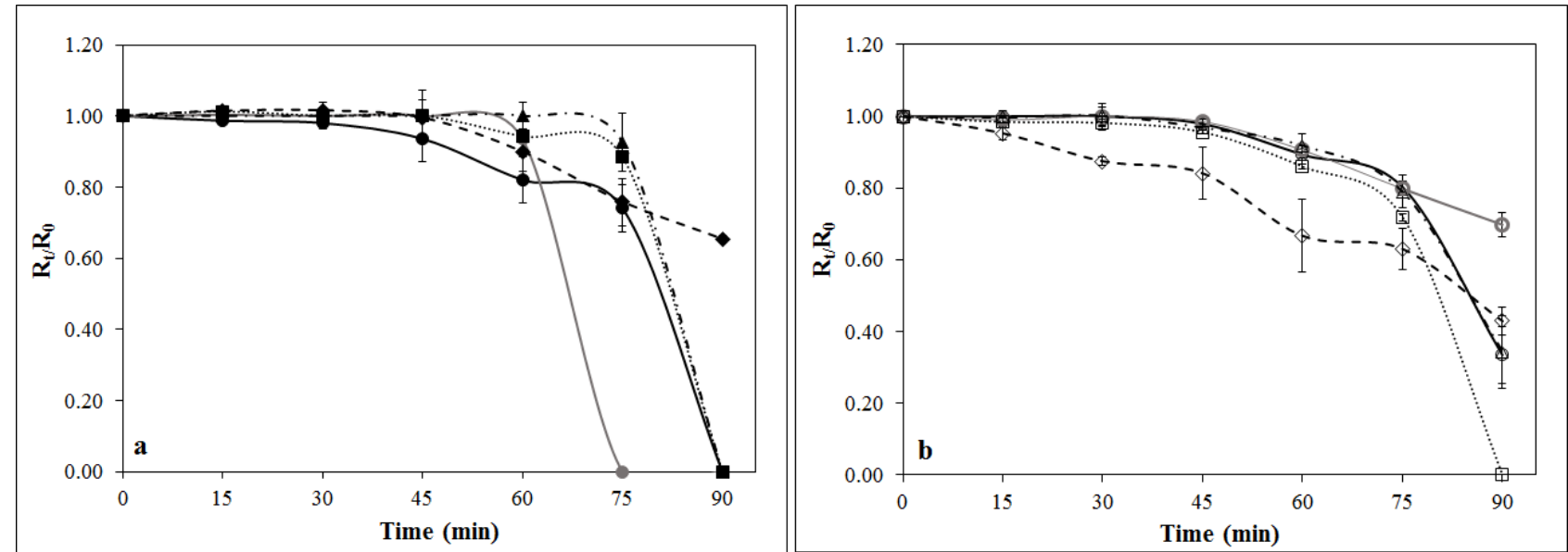
Credit Author Statement

Eleonora Loffredi: Investigation, Formal analysis, Writing- Original draft preparation.

Maria Eletta Moriano: Conceptualization, Investigation, Supervision.

Letizia Loffredi: Investigation, Visualization.

Cristina Alamprese: Conceptualization, Formal analysis, Supervision, Funding acquisition, Writing- Original draft preparation. 


\section{Declaration of interests}

$\bigotimes$ The authors declare that they have no known competing financial interests or personal relationships that could have appeared to influence the work reported in this paper.

$\square$ The authors declare the following financial interests/personal relationships which may be considered as potential competing interests:

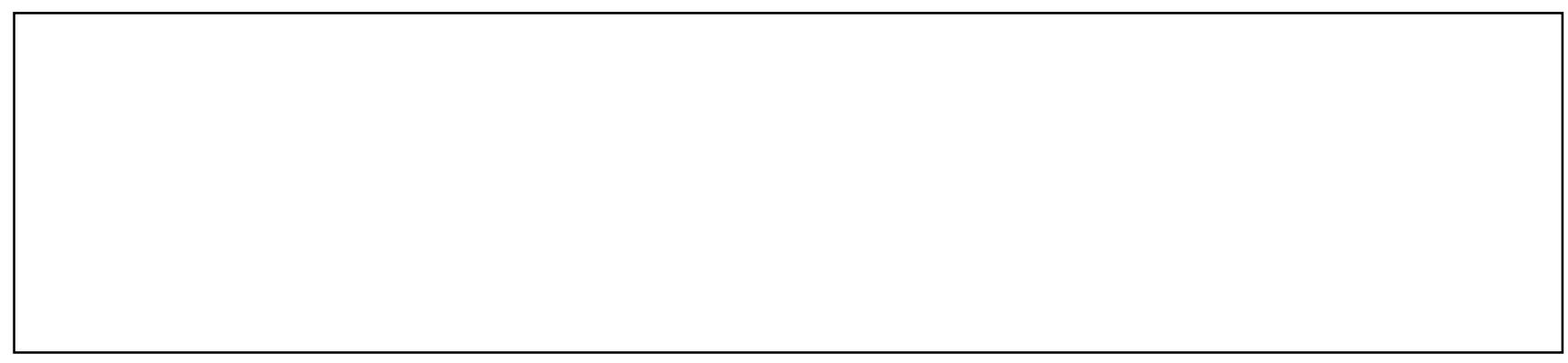

